\title{
Fracture Load and Failure Mode of CAD-on Ceramic Structures
}

\begin{abstract}
This study evaluated the fracture load (Lf) and the failure mode of CAD-on (Ivoclar Vivadent) ceramic structures, testing the hypotheses that $L$ of multilayer structures is governed by the veneering ceramic strength and that chipping is more frequent in multilayer than monolithic structures. Disc-shaped specimens were fabricated as follows: CAD-on- trilayer structure composed of Y-TZP (yttria stabilized tetragonal zirconia polycrystal- IPS e.max ZirCAD) infrastructure, fusion glass-ceramic (IPS e.max CAD Crystall/Connect) and lithium disilicate-based glass-ceramic (IPS e.max CAD); YLD- bilayer structure composed of Y-TZP infrastructure and fluorapatite layering ceramic (IPS e.max Ceram); LDC- monolithic lithium-disilicate glass-ceramic (IPS e.max CAD); and YZW- monolithic Y-TZP (Zenostar $\mathrm{Zr}$ Translucent). The specimens were loaded in compression until failure and fracture surfaces were evaluated using fractographic principles. Lf values were statistically analyzed using the Weibull statistics, Kruskal-Wallis and Dunn tests $(\alpha=0.05)$. YZW $(1329 \mathrm{~N})$ and CAD-on (1085 N) showed the greatest Lf median values, followed by YLD (832 N) and LDC (421 N). All monolithic structures (LDC and YZW) fractured catastrophically and all YLD structures failed by chipping. The CAD-on technique seems to be a very promising fabrication process because it showed high Lf, similar to monolithic zirconia, and small chipping rate.
\end{abstract}

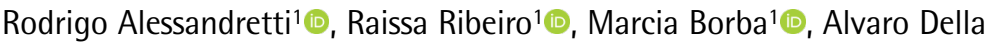 \\ Bona ${ }^{1}$ (I)
}

'Postgraduate Program in Dentistry, Dental School, UPF - Universidade de Passo Fundo, Passo Fundo, RS, Brazil

Correspondence: Alvaro Della Bona, Senior Professor, BR285, km 171, 99052-900 Passo Fundo, RS, Brasil. Tel: +55-54-3316.7000. e-mail:dbona@upf.br

\section{Introduction}

Metal-free ceramic restorations are a popular treatment option, mainly because of structural and esthetic characteristics, which are associated with improvements on materials properties and fabrication technologies that allowed for monolithic and multilayer high crystalline content ceramic restorations (1).

Ceramic restoration manufacturing processes involving sintering or crystallization inevitably cause thermal stresses (thermal incompatibility) that can induce crack propagation (2-6). Further, studies have suggested additional possible causes for ceramic failure, such as: lower modulus of elasticity and fracture toughness of veneer ceramic (5), non-homogeneous layers of ceramic (6); inadequate structural design or insufficient ceramic support $(2,6-8)$; and inadequate ceramic processing, specially the cooling rate $(4,9)$.

Most ceramic restorations have a multi-structural design and, therefore, they have mechanical and fracture behavior associated to these layers (structures) (2). Thus, studies have shown that all-ceramic restorations can fail by chipping or delamination of the ceramic veneer (10-13). Delamination occurs when there is a poor bonding interface between layers $(3,9)$. Nevertheless, chipping appears to be the most recurrent in veneered ceramic restorations (10).

Materials and fabrication techniques for ceramic restorations have much evolved in the last few years. One of the major goals of CAD-CAM ceramic technology is to minimize internal defects and imperfections resulting from other manufacturing methods (14). The CAD-on technique (Ivoclar ${ }^{\circledR}$ ) was introduced as an attempt to reduce manufacturing defects since both structures, the zirconia framework and the lithium disilicate-based glass-ceramic veneer, are fabricated using CAD-CAM technology, then these structures are fused together with a glass, resulting in a trilayer ceramic restoration (15-17).

A previous study evaluated the CAD-on structures and compared them to monolithic and multilayer structures, showing that the fracture resistance of CAD-on structure was high and similar to monolithic zirconia (17). Therefore, the objective of the present study was to evaluate the fracture load (Lf) and failure mode of CAD-on ceramic structures, testing the hypotheses that Lf of multilayer structures is governed by the veneering ceramic strength and that chipping is more frequent in multilayer than monolithic structures.

\section{Material and Methods}

Disc-shaped specimens $(n=20)$ (diameter: $10 \mathrm{~mm}$ and final thickness: $1.8 \mathrm{~mm}$ ) were fabricated from ceramic materials following the ISO 6872: 2015 standard (18) and previous study (17). The four experimental groups were as follows:

CAD-on- A trilayer ceramic structure composed by 1-mm thick layer of zirconia (IPS e.max ZirCAD, Ivoclar Vivadent, Schann, Liechtenstein - YZC), a layer of, approximately, 
$0.1 \mathrm{~mm}$ thick of fusion glass-ceramic (IPS e.max Crystall/ Connect, Ivoclar Vivadent, Schann, Liechtenstein - G) and a 0.7-mm thick lithium disilicate (IPS e.max CAD, Ivoclar Vivadent, Schann, Liechtenstein - LDC) layer. The YZC and LDC blocks were ground (Ferdimat CA51H, São José dos Campos, Brazil) under water cooling, using a diamond stone (Tyrolit TN 634709, Cabreuva, Brazil), into a cylindrical shape, which were cut (Strues Minitron, Copenhagen, Denmark) into disc-shape structures using a diamond disc under water cooling. These structures were polished (Strues Abramin, Copenhagen, Denmark) using a sequence grit of silicon carbide abraded papers (\#600, 800, 1200). The YZC structures were sintered in a Zirkonofen 600/V2 furnace (ZirkonZahn, Gais, South Tyrol, Italy) according to the manufacturer's instructions. The YZC and LDC structures were fused together using $\mathrm{G}$. For this, the G-capsule containing powder and liquid was vibrated (Ivomix, Ivoclar Vivadent, Schann, Liechtenstein) for $10 \mathrm{~s}$, opened, and the material was applied to the surface of the LDC structure that was immediately positioned onto the YZC structure. The three-layer structure was placed under a load of $750 \mathrm{~g}$ and the excess $\mathrm{G}$ was removed with a brush. Fusion of $\mathrm{G}$ and the crystallization of LDC were carried out simultaneously in a Programat EP5000 furnace (Ivoclar Vivadent, Schann, Liechtenstein) following manufacturer's instructions.

YLD- A bilayer ceramic structure simulating a conventional ceramic restoration, composed by a 1-mm thick layer of YZC veneered by a 0.8-mm thick layer of ceramic containing fluorapatite (IPS e.max Ceram, Ivoclar Vivadent, Schann, Liechtenstein -LDT). YZC structure was fabricated as described for CAD-on. The LDT layer was obtained by the traditional layering technique (powder/ liquid). Before application of LDT, a thin layer of IPS e.max ZirLiner (Ivoclar Vivadent, Schann, Liechtenstein) was applied onto YZC and sintered using a Programat EP5000 furnace, according to the manufacturer's instructions. Treated YZC structure was placed in a silicon matrix (Zetaplus, Zhermack SpA, Badia Polesine, Italy) for LDT application. LDT powder and liquid were mixed, applied with a brush onto the treated YZC surface and applied sonic vibration. Excess LDT liquid was removed using absorbent paper. The structure was carefully removed from the matrix and placed into the furnace for sintering following manufacturer's instructions.

LDC- Monolithic specimens ( $1.8 \mathrm{~mm}$ thickness) of LDC were obtained by machining LDC blocks as described for the CAD-on. Specimens were crystallized in a Programat EP5000 furnace, according to the manufacturer's instructions.

YZW- Monolithic specimens (1.8 $\mathrm{mm}$ thickness) of zirconia (Zenostar Zr Translucent, Wieland Dental Technik GmbH \& Co. KG, Pforzheim, Germany - YZW) were obtained by CAD-CAM milling a YZW block $(98.5 \mathrm{~mm}$ diameter disc). For this process, a type IV gypsum cylindrical pattern (Fujirock, GC Corp) was fabricated and scanned (Cerec inLab, Sirona Dental Company, Germany), the data transferred to CAD and the YZW block was milled (InLab MC X5, Sirona Dental Company, Germany) to produced cylinder-shaped blocks that were cut into disc-shape structures as described for the YZC. The disc-shaped specimens were sintered in a Zirkonofen 600/V2 furnace (ZirkonZahn, Gais, South Tyrol, Italy) according to the manufacturer's instructions.

Specimens were covered with a transparent adhesive tape (3M) before compressive loaded to fracture using a biaxial bending test device (piston on three balls) attached to a universal testing machine (EMIC-Instron, DL 2000, São José dos Pinhais, PR, Brazil) with a cross-head speed of $0.5 \mathrm{~mm} / \mathrm{min}$. Tests were performed in $37^{\circ} \mathrm{C}$ distilled water and maximum fracture load (Lf) and number of fracture fragments were registered for each specimen.

Lf values were statistically analyzed using the KruskalWallis and Dunn tests $(\alpha=0.05)$, as well as Weibull statistics. Fracture surfaces were examined using optical microscopy to determine the mode of failure as previously reported (17).

\section{Results}

The median and percentile Lf values (in N), the Weibull modulus and the average (minimum and maximum) number of fragments for the experimental groups are shown in Table 1. The Weibull distribution, which indicates structural reliability, was not statistically different for all experimental groups (Fig. 1). YZW (1329 N) and CAD-on $(1085 \mathrm{~N})$ showed the greatest Lf median values, followed by YLD $(832 \mathrm{~N})$ and LDC $(421 \mathrm{~N})$.

All monolithic structures (LDC and YZW) fractured catastrophically. Most of the CAD-on specimens (85\%) also fractured catastrophically and $15 \%$ failed by chipping.

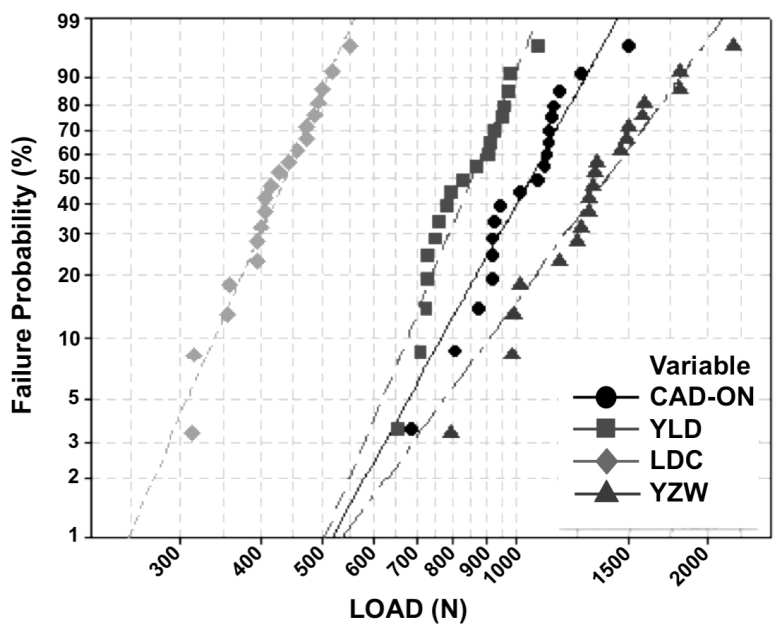

Figure 1. Weibull distribution for the experimental groups. 
All YLD specimens (100\%) failed by chipping (Table 1). The CAD-on group had the highest number of fragments, followed by YZW, LDC and YLD (Table 1).

\section{Discussion}

The multilayer all-ceramic restorations follow the concept of a high strength infrastructure veneered by a very esthetic ceramic. Usually, the strength comes from a high crystalline content ceramic, e.g. zirconia, and the esthetics comes from a glass, a porcelain or a glassceramic, e.g. lithium disilicate-based $(1,14,19)$. Studies have shown that multilayer restorations suffer from chipping, cracking or delamination of the veneer $(11-13,20,21)$, which partially agrees with the results from the present study, mainly for the bilayer structures (YLD). In addition to veneer chipping, these ceramic structures may exhibit a poor interfacial adhesion between structures that can cause delamination $(2,19)$.

In an attempt to minimize these modes of failures, new fabrication techniques, such as CAD-on (15-17) and the monolithic restorations (22) were introduced. The present study evaluated the fracture load of monolithic and multilayer ceramic structures associated with the CAD-on technique (Ivoclar Vivadent). A previous study (17) used same ceramic structures bonded to a dentine analogue material and reported similar results to the present study, meaning, monolithic zirconia and CAD-on structures showed greater fracture loads than the monolithic lithium disilicate-based glass-ceramic.

The CAD-on technique was introduced as more reliable because of using prefabricated blocks and CAD/CAM technology for both infrastructure and veneer layers. Initial reports were promising. One reported that crowns manufactured by the CAD-on technique showed similar fracture resistance to crowns fabricated by the layering technique, but higher than the crowns fabricated by the hot-pressed technique (23).

Zirconia-based and lithium disilicate-based are considered the best materials for monolithic ceramic restorations, mostly because of the fracture resistance and

Table 1. Median values and percentiles of fracture load (Lf in N), statistical grouping $\left({ }^{*}\right)$, Weibull modulus (m), average number (minimum and maximum) of fracture fragments (Nf) and failure mode of experimental groups

\begin{tabular}{lccccc}
\hline \multirow{2}{*}{ Group } & Median $(25 \%-75 \%)^{*}$ & \multirow{2}{*}{$\mathrm{m}^{*}$} & \multirow{2}{*}{ Nf $($ min-max) } & \multicolumn{2}{c}{ Failure mode } \\
\cline { 5 - 6 } & & & & Chipping & Catastrophic \\
CAD-on & $1085(921-1146)^{\mathrm{AB}}$ & $6.0^{\mathrm{A}}$ & $5(2-9)$ & $15 \%$ & $85 \%$ \\
YLD & $832(732-952)^{\mathrm{B}}$ & $8.0^{\mathrm{A}}$ & $2(2-3)$ & $100 \%$ & - \\
LDC & $421(394-484)^{\mathrm{C}}$ & $7.5^{\mathrm{A}}$ & $2.5(2-4)$ & - & $100 \%$ \\
YZW & $1329(1197-1559){ }^{\mathrm{A}}$ & $4.5^{\mathrm{A}}$ & $3(2-4)$ & - & $100 \%$ \\
\hline
\end{tabular}

*Values followed by same letters in columns are not statistically different ( $>0.05)$. esthetics (24). In relation to traditional restorations, the monolithic restorations minimize problems associated with more complex traditional fabrication, as well as the presence of different thermal gradients and residual stresses and delamination from infrastructure (3). It has been reported that zirconia-based and lithium disilicate-based crowns offer a better response against the inherent restorationtooth interfacial stresses, inhibiting the onset of cracking, which corroborates with the fracture behavior shown for same structures in the present study. However, it should be noted that the integrity of monolithic restorations can be compromised by manufacturing defects, inadequate preparations, improper sitting, and service fatigue (25).

$A n$ in vitro study evaluated the fatigue behavior and manufacturing reliability of monolithic (IPS e.max CAD) and bilayer crowns (IPS e.max ZirCAD + IPS e.max Ceram). The monolithic crowns showed fractures exposing the preparation with a mean Lf value of $2576 \mathrm{~N}$, which was greater than the bilayer crowns (1195 N) that showed only chipping of the veneer ceramic (22). The present study evaluated these ceramic structures (LDC and YLD) following ISO 6872: 2015 standard (18) and previous study (17), but obtained different load values ( $421 \mathrm{~N}$ and $832 \mathrm{~N}$ ), which can be explained by difference in test specimens and test design. Nevertheless, chipping in traditional all-ceramic structures (infrastructure + veneer) is often associated to significant differences in strength and elastic moduli between infrastructure and veneer ceramics (1). This may explain the veneer chipping of all Y-TZP crowns (22). In addition, it has been shown that multilayer Y-TZP structures submitted to compressive load can produce interfacial gaps that could lead to chipping (19). Such chipping failures have been reported in several clinical studies $(20,21)$, partially confirming the second study hypothesis.

Veneered Y-TZP ceramic structures (YLD) showed 100\% failures by chipping. One possible explanation is the presence of porosities and inclusions in the veneering ceramic and at ceramics interface, which are not rare when using the layering technique. In addition, this traditional technique is very sensitive to several factors, such as: experience of the dental laboratory technician; homogeneity of the ceramic paste (mixing powder and liquid); sintering rates; and the coefficient of thermal expansion of the ceramics (1). If one consider this experimental group (YLD) alone, the first study hypothesis would be confirmed. Yet, comparing the data (mode of failure and Lf) between the monolithic (LDC) and the multilayer structure CAD-on, 
which uses LDC as the veneering ceramic, the first study hypothesis is only partially confirmed, suggesting that a strong bond, as achieved by the fusion glass, is more relevant than the strength difference between infrastructure and veneer ceramics. In addition, the difference in fracture behavior may be explained by the difference in fabrication processes of YLD (layering) and CAD-on (CAD-CAM), which results in a stronger ceramic (LDC compared to LDT).

In the present study, Lf data was also analyzed using Weibull distribution (Fig. 1) that showed similar structural reliability for the evaluated ceramics because the $95 \% \mathrm{Cl}$ of all Weibull moduli $(\mathrm{m})$ overlapped, which agrees with a previous work (17).

CAD-on structures showed similar Lf and mode of failure to monolithic zirconia (YZW), except for three CADon specimens that chipped. Chipping was the dominant fracture mode only for the bilayer structure (YLD). These results partially confirmed the second study hypothesis and are in agreement with a 1-year follow-up randomized controlled clinical trial (26). Thus, monolithic structures resisted to their cohesive strength and only showed catastrophic fractures, satisfying one of the main reasons for their introduction: avoiding ceramic chipping.

The results of the present study strengthen the findings of previous reports (15-17) on the CAD-on technique, which seems to be a very promising fabrication process because it showed high Lf, similar to monolithic zirconia, and small chipping rate.

\section{Resumo}

Este estudo avaliou a carga de fratura (Cf) e o modo de falha de estruturas cerâmicas fabricadas pela técnica CAD-on (Ivoclar Vivadent), testando as hipóteses de que a Cf das estruturas multicamadas é governada pela resistência da cerâmica de cobertura e o lascamento é mais frequente nas estruturas em multicamadas do que em monolíticas. Corpos de prova no formato de disco formam fabricados da seguinte forma: CAD-onestrutura de 3 camadas composta por infraestrutura de Y-TZP (zircônia tetragonal parcialmente estabilizada por itria - IPS e.max ZirCAD), vidro de fusão (IPS e.max CAD Crystall/Connect) e cobertura de cerâmica vitrea a base de dissilicato de lítio (IPS e.max CAD); YLD- estrutura de 2 camadas composta por infraestrutura de Y-TZP e cobertura de cerâmica (IPS e.max Ceram); LDC- monolítico em cerâmica vitrea a base de dissilicato de lítio (IPS e.max CAD); e YZW- monolitico em Y-TZP (Zenostar Zr Translucent). Os corpos de prova foram testados sob carga de compressão até a falha e as fraturas avaliadas seguindo os principios da fractografia. Os valores de Lf foram analisados estatisticamente usando as estatísticas de Weibull, Kruskal-Wallis e Dunn $(\alpha=0,05)$. YZW $(1329 \mathrm{~N})$ e CAD-on $(1085 \mathrm{~N})$ apresentaram os maiores valores medianos de $\mathrm{Cf}$, seguidos por YLD (832 N) e LDC (421 N). Todas as estruturas monoliticas (LDC e YZW) fraturaram catastroficamente e todas as estruturas YLD falharam por lascamento. A técnica CAD-on parece ser um processo de fabricação bastante promissor pois mostrou alta Cf, similar a zircônia monolitica, e baixa taxa de lascamento.

\section{Acknowledgments}

This study was partially supported by PROSUC-Capes and CNPq do Brazil (grants \#302587/2017-9)

\section{References}

1. Della Bona A. Bonding to ceramics: scientific evidences for clinical dentistry. 1. ed. São Paulo: Artes Médicas, 2009.

2. Della Bona A, Anusavice KJ, Dehoff PH. Weibull analysis and flexural strength of hot-pressed core and veneered ceramic structures. Dent Mater 2003;19:662-669.

3. Zhang Y, Lee JJW, Srikanth R, Lawn BR. Edge chipping and flexural resistance of monolithic ceramics. Dent Mater 2013;29:1201-1208.

4. Benetti P, Kelly JR, Della Bona A. Analysis of thermal distributions in veneered zirconia and metal restorations during firing. Dent Mater 2013;29:1166-1172.

5. Benetti P, Pelogia F, Valandro LF, Bottino MA, Della Bona A. The effect of porcelain thickness and surface liner application on the fracture behavior of a ceramic system. Dent Mater 2011;27:948-953.

6. Corazza PH, Feitosa SA, Borges AL, Della Bona A. Influence of convergence angle of tooth preparation on the fracture resistance of Y-TZP-based all-ceramic restorations. Dent Mater 2013;29:339-347.

7. Della Bona A, Borba M, Benetti $P$, Duan $Y$, Griggs JA. Three-dimensional finite element modelling of all-ceramic restorations based on micro-CT. J Dent 2013;41:412-419.

8. Mallmann F, Rosa L, Borba M, Della Bona A. Effect of screw-access hole and mechanical cycling on fracture load of 3-unit implant-supported fixed dental prostheses. J Prosthet Dent 2018;119:124-131.

9. Benetti P, Kelly JR, Sanchez M, Della Bona A. Influence of thermal gradients on stress state of veneered restorations. Dent Mater 2014;30:554-563.

10. Sailer I, Fehér A, Filser F, Gauckler $\sqcup$, Luthy $H$, Hammerle CHF. Five year clinical results of zirconia frameworks for posterior fixed partial dentures. Int J Prosthodont 2007;20:383-388.

11. Lohbauer U, Scherrer SS, Della Bona A, Tholey M, van Noort R, Vichi $A$, et al. ADM guidance-Ceramics: all-ceramic multilayer interfaces in dentistry. Dent Mater 2017;33:585-598.

12. Cesar PF, Della Bona A, Scherrer SS, Tholey M, van Noort R, Vichi A, et al. ADM guidance-Ceramics: Fracture toughness testing and method selection. Dent Mater 2017;33:575-584.

13. Scherrer SS, Lohbauer U, Della Bona A, Vichi A, Tholey MJ, Kelly JRet al. ADM guidance-Ceramics: guidance to the use of fractography in failure analysis of brittle materials. Dent Mater 2017;33:599-620.

14. Griggs JA. Recent advances in materials for all-ceramic restorations. Dent Clin North Am 2007;51:713-727.

15. Basso GR, Moraes RR, Borba M, Griggs JA, Della Bona A. Flexural strength and reability of monolithic and trilayer ceramic structures obtained by the CAD-on technique. Dent Mater 2015;31:1453-1459.

16. Basso GR, Moraes RR, Borba M, Duan Y, Griggs JA, Della Bona A. Reliability and failure behavior of CAD-on fixed partial dentures. Dent Mater 2016;32:624-630.

17. Alessandretti $R$, Borba $M$, Benetti $P$, Corazza PH, Ribeiro R, Della Bona A. Reliability and mode of failure of bonded monolithic and multilayer ceramics. Dent Mater 2017;33:191-197.

18. International Organization for Standardization. ISO 6872:2015 dentistry - ceramic materials.

19. Borba M, Araújo MD, Lima E, Cesar PF, Griggs JA, Della Bona A. Flexural strength and failure modes of layered ceramic structures. Dent Mater 2011;27:1259-1266.

20. Sailer I, Makarov NA, Thoma DS, Zwahlen M, Pjetursson BE. All-ceramic or metal-ceramic tooth-supported fixed dental prostheses (FDPs) A systematic review of the survival and complication rates. Part I: Single crowns (SCs). Dent Mater 2015;31:603-623.

21. Pjetursson BE, Sailer I, Makarov NA, Zwahlen M, Thoma DS. All-ceramic or metal-ceramic tooth-supported fixed dental prostheses (FDPs) A systematic review of the survival and complication rates. Part II: Multiple-unit FDPs. Dent Mater 2015;31:624-639.

22. Guess PC, Zavanelli RA, Silva NR, Bonfante EA, Coelho PG, Thompson VP. Monolithic CAD/CAM lithium disilicate versus veneered Y-TZP crowns: comparison of failure modes and reliability after fatigue. Int J Prosthodont 2012;23:434-442.

23. Schmitter M, Mueller D, Rues S. Chipping behaviour of all-ceramic crowns with zirconia framework and CAD/CAM manufactured veneer. 
J Dent 2012:40:154-162

24. Pieger S, Salman A, Bidra AS. Clinical outcomes of lithium disilicate single crowns and partial fixed dental prostheses: a systematic review. J Prosthet Dent 2014;112:22-30.

25. Zhang Y, Mai Z, Barani A, Bush M, Lawn B. Fracture-resistant monolithic dental crowns. Dent Mater 2016;32:442-449.

26. Grohmann P, Bindl A, Hämmerle C, Mehl A, Sailer I. Three-unit posterior zirconia-ceramic fixed dental prostheses (FDPs) veneered with layered and milled (CAD-on) veneering ceramics: 1-year follow-up of a randomized controlled clinical trial. Quintessence Int 2015;46:871-880.

Received October 30, 2018 Accepted February 8, 2019 